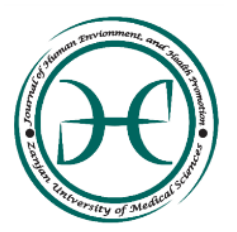

Journal of Human, Environment, and Health Promotion

Journal homepage: www.zums.ac.ir/jhehp

\title{
The Effect of Washing and Peeling on Reduction of Dithiocarbamates Residues in Cucumber and Tomato
}

\author{
Mohammad Reza Mehrasbi a,*, Rohangiz Moradjoo a, Mehran Mohseni b, Koorosh \\ Kamali $^{c}$, Zohre Farahmankia ${ }^{d}$, Jafar Taran ${ }^{\text {a }}$ \\ ${ }^{a}$ Department of Environmental Health Engineering, School of Public Health, Zanjan University of \\ Medical Sciences, Zanjan, Iran. \\ ${ }^{b}$ Food and Drug Control Department School of Pharmacy, Zanjan University of Medical Sciences. \\ Zanjan, Iran. \\ ${ }^{c}$ Department of Statistic, School of Public Health, Zanjan University of Medical Sciences. Zanjan, \\ Iran. \\ ${ }^{d}$ School of Health ,Head of Chemistry Laboratory, Zanjan University of Medical Sciences. Zanjan, \\ Iran.
}

*Corresponding author.E-mail address: zmehr@zums.ac.ir

\section{A R T I C L E I N F O}

Article history:

Received August 17, 2015

Accepted September 22, 2015

Article Type:

Original Article

DOI: 10.29252/jhehp.1.2.99

\section{Keywords:}

Dithiocarbamates

Cucumber

Tomatoes

Colorimetric

$\mathrm{CS}_{2}$

\section{A B S T R A C T}

Background: Dithiocarbamates, the main group of fungicides, are used to control about 400 pathogens in more than 70 crops. These pesticides are widely applied to crops including potato, cereal, apple, pear and leafy vegetables throughout the world since 1960. From the late 1980s, using these fungicides has caused much debate among regulators about their long-term effects on consumers and occupational users.

Method: In this study the residues of Dithiocarbamates in cucumber and tomato using the colorimetric method (Keppel method) was measured. Respectively 80 and 45 samples of greenhouse cucumber and tomato were collected from Zanjan vegetables center in autumns and winter 2013. The samples were analyzed in 4 treatments of: unwashed, washing with water, washing whit detergent and peeling.

Result: The results showed that the average concentration of Dithiocarbamates residues in unwashed greenhouse cucumber and tomatoes were $384.5 \mu \mathrm{g} / \mathrm{kg}$ and $65 \mu \mathrm{g} / \mathrm{kg}$ respectively. $35 \%$ and $5 \%$ of unwashed and water washed cucumber and tomato samples (respectively) had higher Dithiocarbamates residue than MRL recommended by Institute of Standards and Industrial Research of Iran $(0.5 \mathrm{mg} / \mathrm{kg})$.

Conclusion: The treatments of washing and peeling had significant effect on the reduction of Dithiocarbamates residues in the all samples.

\section{Introduction}

Dithiocarbamates $\left(\mathrm{DTC}_{\mathrm{s}}\right)$ belong to the family of Carbamate and organophosphate pesticides, which have been used in agriculture as fungicide for more than 80 years and they widely used as vulcanization accelerators in the

To cite: Mehrasbi MR, Moradjoo R, Mohseni M, Kamali K, Farahmankia Z, Taran J. The Effect of Washing and Peeling on Reduction of Dithiocarbamates Residues in Cucumber and Tomato. J Hum Environ Health Promot. 2016; 1(2): 99-104. 
rubberindustry [1-3] They can control approximately 400 pathogens of more than 70 crops [4].

DTCS are categorized into three groups of Dimethylditiocarbamate (DMDS), ethylenbis (Dithiocarbamates) (EBDS) and propylenbis (Dithiocarbamates) (PBDS) [5]. EBDS and PBDS are almost insoluble in water and organic solvent. DMDS (e.g. Thiram, Ziram and ferbam) are slightly soluble in water and some polar organic solvents. It is well known that Dithiocarbamates residues in food system are carcinogenic in laboratory animals [6].

Extreme activity of Dithiocarbamates mostly related to their metal- chelating ability and high affinity for proteins containing the SH-groups $[1,7]$. The most important transformation products of $\mathrm{DTC}_{\mathrm{s}}$ are Ethylenthiourea (ETU) and propylene thiourea (PTU) which cause various pathogenic, mutagenic and teratogenic $[8$, 9]. DTC $C_{S}$ are non-systemic fungicides and in use they are sprayed on the plant, so the residue of which mostly remain on the surface of the crop [10]. In recent years the scientific reports show their presence in foods, drinks and environment [11, 12]. DTC $_{s}$ are not stable and cannot extracted and analyzed directly.

Because of harmful effects of DTC national and international health related organizations are established defined limitations for DTC $_{\text {s. The main limitation }}$ is maximum residue levels (MRLs) [13].

The MRLs refer to total $\mathrm{DTC}_{\mathrm{s}}$ determined as $\mathrm{CS}_{2}$ evolved during acid digestion and expressed as $\mathrm{mgCS}_{2} / \mathrm{kg}$. According to FAO/WHO standards the MRLs of DTC $_{s}$ in tomato and cucumber are $2 \mathrm{mg} / \mathrm{kg}$ [14]. Institute of Standards and Industrial Research of Iran has established the MRLs of $\mathrm{DTC}_{\mathrm{s}}$ as 0.5 $\mathrm{mg} / \mathrm{kg}$ in tomato and cucumber [13]. Tomato and cucumber is two main vegetables in Iranian diet. The per capita of consumption of cucumber and tomato are $23.078 \mathrm{~kg} / \mathrm{year}$ and $62.6 \mathrm{~kg} / \mathrm{year}$ respectively [15]. Insolubility of DTC $\mathrm{D}_{S}$ in water and other solvents cause some difficulties for extraction and measurement of their residue on the crops [16] On the other hand, if the concentration of DTC $S$ residues on the crops be high, there is a doubt about removing of the $\mathrm{DTC}_{S}$ residue from the surface of the crop by washing the crops with water and there in no any documented study about it.

In the present experimental study report the effects of washing and peeling on reduction of DTCs residues on the cucumber and tomato is evaluated.

\section{Material and Methods}

\subsection{Chemicals and solutions}

All chemicals were analytical grade obtained from Merck. The color reagent (solution of copper Acetate monohydrate ) were prepared by $0.024 \mathrm{~g}$ cupper acetate monohydrate in $55.6 \mathrm{ml}$ of diethanolamine in $500 \mathrm{ml}$ ethanol and stored at $5 \dot{\mathrm{c}}$ protected from light. Hydrolysis reagent was prepared with $100 \mathrm{ml}$ hydrochloric acid $(37 \%)$ and $50 \mathrm{ml}$ reagent water. Lead acetate solution was prepared by dissolving of $30 \mathrm{~g}$ of $30 \% \mathrm{~Pb}\left(\mathrm{C}_{2} \mathrm{H}_{3} \mathrm{O}_{2}\right)_{2}$. $3 \mathrm{H}_{2} \mathrm{O}$ in $100 \mathrm{ml}$ reagent water.

\subsection{Sample preparation}

The greenhouse tomato and cucumber samples were collected from the distribution center of fruit and vegetables of Zanjan in December, January and February of 2012. Samples were divided into 4 groups (treatments) including unwashed, washed with water, washed with detergent and peeled. For washing with detergent an anionic detergent which is used for dish washing and in Iran named Jaam was used.

\subsection{Analysis}

The analytical method for measurement of DTC $\mathrm{D}_{S}$ in this research was based on the conversion of the residue of the DTCS to $\mathrm{CS}_{2}$ (Cullen method) [17]. A modification of this design was proposed by Thier and Zeumer [18-20].

In the process of acid decomposition of DTCs, in the presence of stannous chloride as a reducing agent, the cupric complex is formed from the reaction between $\mathrm{CS}_{2}$ and the copper (II) acetate monohydrate which is measured at $435 \mathrm{~nm}$ by spectrophotometry method. In this 
research, a two neck round- bottom boiling flask placed in a heating mantel connected to a traditional distillation system was used for acid decomposition of DTCS and $\mathrm{CS}_{2}$ collection. The distillation system consisted of 3 traps which are connected to the condenser.

The first trap contains $20 \mathrm{~mL}$ of $\mathrm{NaOH}$ $(4 \mathrm{~N})$ solution, the second trap contains 10 $\mathrm{mL}$ of Lead acetate solution, and the third trap contains $15 \mathrm{~mL}$ of color reagent. Both $\mathrm{NaOH}$ and lead acetate solutions were used to purify the $\mathrm{CS}_{2}$ formed, removing volatile interferences, mainly $\mathrm{H} 2 \mathrm{~S}$ and $\mathrm{CS}_{2}$.

$100 \mathrm{gr}$ of grinded sample, $2 \mathrm{~g}$ of $\mathrm{SnCl}_{2}$, and $100 \mathrm{ml}$ of hydrolysis reagent were put in the tow- neck round bottom boiling flask which was heated for $45 \mathrm{~min}$. and the acid decomposition of $\mathrm{DTC}_{\mathrm{s}}$ took place in the presence of $\mathrm{HCl}$.

After cooling of product of distillation, the solution of trap3 was diluted to $25 \mathrm{ml}$ by ethanol. After 15 minute, the absorbance of the solution was measured at $435 \mathrm{~nm}$ against the reagent blanks prepared in the same way.

The standard curve of the $\mathrm{CS}_{2}$ was prepared by CS2 calibration solution (Fig. 1).Known volumes of the CS2 stock solution were transferred to $25 \mathrm{~mL}$ volumetric flasks, $15 \mathrm{~mL}$ of the color reagent was added, the volume was completed with ethanol, and the solution was allowed to stand for $15 \mathrm{~min}$. The absorbance was measured by spectrophotometer (DR- 5000).

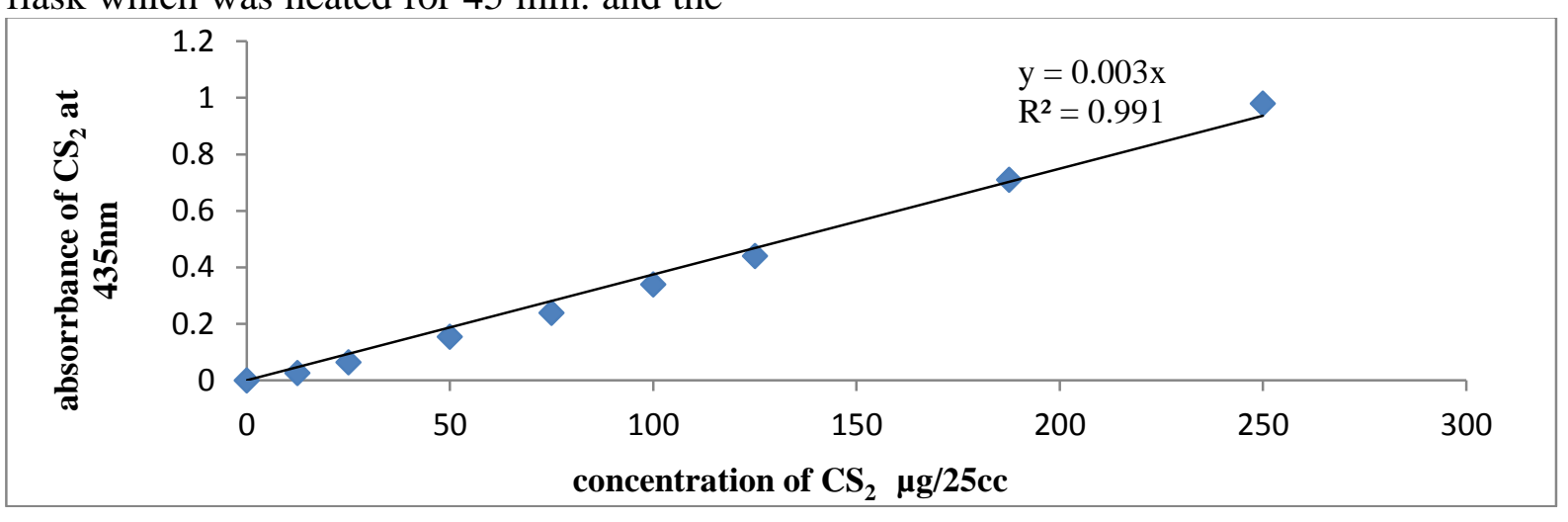

Fig.1: Standard curve of absorbance against $\mu \mathrm{g} \mathrm{CS} \mathrm{S}_{2}$ for determination of DTC $\mathrm{D}_{\mathrm{S}}$ residues.

\subsection{Quality control of the method}

The LOD (limit of detection), LOQ (limit of quantification) and the percent of recovery were determined for quality control of the analysis method [21].

The tomato and cucumber samples were spiked with standard solution of Maneb and Mancozeb and after analysis of the samples the amounts of LOD, LOQ and recovery were determined. The LOD Table 1: The results of the recovery experiments.

\begin{tabular}{|c|c|c|c|c|}
\hline Sample type & Spiked solution & $\begin{array}{c}\text { Concentration of standard } \\
\text { solution }(\mu \mathrm{g} / \mathrm{kg})\end{array}$ & $\begin{array}{c}\text { Number } \\
\text { Of replicate }\end{array}$ & Mean Recovery (\%) \\
\hline \multirow{9}{*}{ Tomato } & \multirow{3}{*}{$\begin{array}{l}\text { Commercial } \\
\text { Mancozeb }\end{array}$} & 8.5 & 3 & 97 \\
\hline & & 14 & 3 & 95 \\
\hline & & 17 & 3 & 96 \\
\hline & \multirow{3}{*}{$\begin{array}{l}\text { Standard } \\
\text { Mancozeb }\end{array}$} & 14 & 3 & 115 \\
\hline & & 17 & 3 & 103 \\
\hline & & 34 & 3 & 92 \\
\hline & \multirow{3}{*}{$\begin{array}{l}\text { Standard } \\
\text { Maneb }\end{array}$} & 14 & 3 & 110 \\
\hline & & 17 & 3 & 110 \\
\hline & & 34 & 3 & 88 \\
\hline
\end{tabular}

and LOQ of the method were $18 \mu \mathrm{g} / \mathrm{kg}$ and $60 \mu \mathrm{g} / \mathrm{kg}$ respectively. In order to statistical analysis of the DTCS residues concentrations with values less than LOD, half of the determined LOD (1/2 LOD) was considered in calculations [22].

The results of the recovery experiments are shown in table 1 . All of the earned recoveries were between $\% 88$ and $\% 115$. 


\section{Results}

After quality control tests, the samples were divided into the 4 treatments (unwashed, water washed, washing with detergent and peeled) and the $\mathrm{DTC}_{\mathrm{S}}$ residues were measured. Tables 2 and 3 shows the mean concentrations of DTC residues in the samples briefly. In the table 4 the reduction of $\mathrm{DTC}_{\mathrm{S}}$ residues, after washing and peeling of samples are shown.

Table 2: The concentrations of $\mathrm{DTC}_{\mathrm{S}}$ residues in the cucumber samples as $(\mu \mathrm{g} / \mathrm{kg}) \mathrm{CS}_{2}$

\begin{tabular}{ccccccc}
\hline Treatment & Sample size & $\begin{array}{c}\text { Mean } \\
(\boldsymbol{\mu g} / \mathbf{k g})\end{array}$ & $\begin{array}{c}\text { Maximum } \\
(\boldsymbol{\mu g} / \mathbf{k g})\end{array}$ & $\begin{array}{c}\text { Minimum } \\
(\boldsymbol{\mu g} / \mathbf{k g})\end{array}$ & $\begin{array}{c}\text { Standard } \\
\mathbf{e r r o r}\end{array}$ & $\begin{array}{c}\text { Mod } \\
(\boldsymbol{\mu g} / \mathbf{k g})\end{array}$ \\
\hline Unwashed & 80 & 384.5 & 2233 & $9(1 / 2$ LOD $)$ & 119 & 183 \\
$\begin{array}{c}\text { Washed with } \\
\text { Water }\end{array}$ & 80 & 124 & 663 & $9(1 / 2$ LOD $)$ & 36.4 & 43 \\
$\begin{array}{c}\text { Washed with } \\
\text { Detergent }\end{array}$ & 80 & 52 & 293 & $9(1 / 2$ LOD $)$ & 15.6 & 14.5 \\
$\quad$ Peeled & 80 & 17.5 & 53 & $9(1 / 2$ LOD $)$ & 3.7 & 9 \\
\hline
\end{tabular}

Table 3: The concentrations of DTC $\mathrm{S}_{\mathrm{S}}$ residues in the tomato samples as $(\mu \mathrm{g} / \mathrm{kg}) \mathrm{CS}_{2}$

\begin{tabular}{ccccccc}
\hline treatment & Sample size & $\begin{array}{c}\text { Mean } \\
(\boldsymbol{\mu g} / \mathbf{k g})\end{array}$ & $\begin{array}{c}\text { Maximum } \\
(\boldsymbol{\mu g} / \mathbf{k g})\end{array}$ & $\begin{array}{c}\text { Minimum } \\
(\boldsymbol{\mu g} / \mathbf{k g})\end{array}$ & $\begin{array}{c}\text { Standard } \\
\mathbf{e r r o r}\end{array}$ & $\begin{array}{c}\text { Mod } \\
(\boldsymbol{\mu g} / \mathbf{k g})\end{array}$ \\
\hline Unwashed & 45 & 65 & 190 & $9(1 / 2$ LOD $)$ & 16 & 33 \\
$\begin{array}{c}\text { Washed with } \\
\text { Water }\end{array}$ & 45 & 22 & 93 & $9(1 / 2$ LOD $)$ & 6.3 & $9(1 / 2$ LOD $)$ \\
$\begin{array}{c}\text { Washed with } \\
\text { Detergent } \\
\text { Peeled }\end{array}$ & 45 & 11 & 40 & $9(1 / 2$ LOD $))$ & 2 & $9(1 / 2$ LOD $)$ \\
\hline
\end{tabular}

Table 4: The reduction of $\mathrm{DTC}_{\mathrm{S}}$ residue in different treatments in compare with unwashed treatment.

\begin{tabular}{cccc}
\hline Sample & Washed with Water & $\begin{array}{c}\text { Concentration } \\
\text { Washed }\end{array}$ & Peeled \\
\hline Cucumber & 67.75 & 86.47 & 95.4 \\
Tomato & 66.3 & 83 & 84.6 \\
\hline
\end{tabular}

The mean concentrations of DTC $_{S}$ residues in unwashed cucumber and tomato samples were $384.5(\mu \mathrm{g} / \mathrm{kg})$ and $65(\mu \mathrm{g} / \mathrm{kg})$ respectively. The minimum DTCS residues concentrations in the all of the samples were lower than the measured LOD value but in statistical calculations 1/2 LOD was considered.

In $35 \%$ and $5 \%$ of unwashed and 
washed with water greenhouse cucumber samples, DTCS residues were higher than the recommended MRLs of Institute of Standards and Industrial Research of Iran and none of samples were higher than the codex recommended MRLs.

The results showed that, the washing with water, with detergent and peeling can reduce the DTCS concentration in cucumber by $68 \%, 86 \%$ and $95 \%$ respectively. These reductions in tomato samples were $66 \%, 83 \%$ and $84 \%$ respectively. Washing with detergent reduced the DTCS residues only about $18 \%$ more than washing with water, so it can be conclude that water has the main role in cleaning of DTCS residues from the surface of the crops.

In order to determining the differences between the results in different treatments, statistical analysis of post Hoc-Bonferrony was used. This test showed that washing with water and detergent and peeling reduce the DTC , residue significantly. On the other hand in comparison with unwashed samples, the DTC $\mathrm{S}_{S}$ residue in washed and peeled samples are low $(P<0.05)$.

The results showed that there is no significant decreasing between treatments of washed with detergent and peeled with treatment of water washed samples ( $P$ > $0.05)$ as well as there is no significant decrease between treatments of peeled and washed with detergent $(P>0.05)$.

As mentioned before, it means that the most of DTC $_{S}$ residues is washed with water. Peeling cause the most decreasing in DTC $_{S}$ residue in tomato and cucumber and this reduction shows that the most values of DTCs concentrations is accumulated on the surface of the samples. The results showed that washing can reduce the concentration of $\mathrm{DTC}_{S}$ by 85 percent but the best way of control is peeling.

\section{Discussion and Conclusion}

The study showed that the measurement of DTC $_{S}$ residues in cucumber and tomato using Cullen method is simple and valid with the method detection limit of 18 $\mu \mathrm{g} / \mathrm{kg}$. The results showed that $\% 35$ of the cucumbers had DTC residues higher than recommended MRL of Institute of Standards and Industrial Research of Iran. This is an important alarm and establishing a methodological program for sampling and analysis of the crops in Iran.

If the concentration of residue be very high, washing with water or detergent cannot decrease the residue, lowers than recommended MRLs. Meanwhile it is recommended that in any cases, washing with water is necessary and peeling is the most efficient way for reduction of DTC $S$ residues in cucumber and tomato.

Acknowledgement

Authors are thankful to head department of Environmental health engineering, group administer and workers of universal analysis laboratory of Zanjan health state college.

\section{References}

1. WHO DP. Ethylenethiourea and Propylenethiourea: A General Introduction. WHO: Geneva; 1988.

2. Crnogorac G, Schwack W. Residue Analysis of Dithiocarbamate Fungicides. TrAC: Trends Analyt Chem. 2009; 28(1): 40-50.

3. Malik AK, Faubel W. Methods of Analysis of Dithiocarbamate Pesticides: A Review. Pest Manag Sci. 1999; 55(10): 965-70.

4. Food Safety Pesticide Residue, European Commission, Brusseels. 2002, Available from: URL: http://europa.eu.int/com/food/phps/pest/ind ex en.htm.

5. Cajka T, Riddellova K, Zomer P, Mol H, Hajslova J. Direct Analysis of Dithiocarbamate Fungicides in Fruit by Ambient Mass Spectrometry. Food Addit Contam Part A. 2011; 28(10): 1372-82. 
6. Graham SL, Hausen WH. Bull Environ Contamin Toxical. 1972; (7): 19.

7. Bazzi L, Zougagh M, Salghi R, Hormatallah A, Lemerhyeratte A, Mihit A, et al. Pesticide Residue Monitoring in Green Beans from Souss-Massa (Morocco) and Half-Life Times of Dithiocarbamate Fungicide on Green Beans after Field Treatments by Mancozeb and Mefenoxam. Orient J Chem. 2009; 25(3): 461.

8. Allain P, Krari N. Diethyldithiocarbamate, Copper and Neurological Disorders. Life Sci. 1991; 48(3): 291-9.

9. Miller DB. Neurotoxicity of Pesticidal Carbamates. Neurobehav Toxicol Teratol. 1982; (4): 779-87.

10. Pesticide Residue in Food-1993. Report of the Joint Metting of the FAO Panel of Experts on Pesticide Residues in Food and the Environment and the WHO Expert Group on Pesticide Residues. FAO Plant Production and Protection Paper. Rom: Italy; 1994.

11. WHO. The WHO Recommended Classification of Pesticides by Hazard and Guidelines to Classification. WHO. IPCS: IOMC; 2005.

12. Monser L, Adhoum N. Sep. Purif. Technol. 2002; 26: 137.

13. Pesticides -Maximum Residue Limit of Pesticides - Fruit Vegetables. Institute Stand Ind Res Iran. 2009.12581.

14. Codex Alimentarius, Volume 2A, Part 1 - 2000. Portion of Commodities to Which MRLs Apply.
15. Statistical Center of Iran. Resultes of Capitation of Agricalture in 2003.

16. Alder L, Greulich K, Kempe G, Vieth B. Residue Analysis of 500 High Priority Pesticides: Better by GC-MS or LCMS/MS. Mass Spectrom Rev. 2006; 25(6): 838-65.

17. Cullen TE. Spectrophotometric Determination of Dithiocarbamate Residues in Food Crops. Anal Chem. 1964; 36(1): 221-4.

18. Thier HP, Zeumer H, Eds. Dithiocarbamate and Thiuram Disulfide Fungicides In Manual of Pesticide Residues Analysis. Pestic Commission: Germany. 1987; (1): 432.

19. Caldas ED, Miranda MC, Conceição MH, De Souza LC. Dithiocarbamates Residues in Brazilian Food and the Potential Risk for Consumers. Food Chem Toxicol. 2004; 42(11): 1877-83.

20. Keppel GE. Collaborative Study of the Determination of the Dithiocarbamate Residues by a Modified Carbon Disulfide Evolution Method. J Assoc Off Anal Chem. 1971; 54(3): 528-32.

21. Sharma KK. Pesticide Residue Analysis Manual. Directorate of Information and Publications of Agriculture, Indian Council of Agricultural Research. AGRIS. 2007; 1-293.

22. Office of Pesticide Programs. Assining Values to Nondetected/non-Uantifid Pesticide Residues in Human Health Food Exposure Assesments. US Environ Prot Agency Washington: DC; 20460. 2000. 